\title{
OS INVESTIMENTOS NA EDUCAÇÃO INFANTIL MUNICIPAL DE OTONI NO PERÍODO 2014/2017: UMA ANÁLISE NO VALE DO MUCURI - MG
}

Thayse Ramos Cardoso Pinto ${ }^{1}$

Simão Pereira da Silva²

\section{RESUMO}

No Brasil, os movimentos e as reivindicações sociais tiveram relação direta com os direitos alcançados pela educação infantil (EI). Como consequência, a Constituição Federal de 1988 determinou aos Municípios a oferta da El. Contudo, a administração pública da El segue com uma postura empírica e assistencialista. Neste artigo, analisaram-se os investimentos públicos na El do Município de Teófilo Otoni (no vale do Mucuri em MG) no período de 2014 a 2017, por meio da pesquisa bibliográfica, documental e de campo. Na execução financeira, constataram-se sérias discrepâncias entre o orçamento e sua execução, bem como percebeu-se que os investimentos realizados não suprem a demanda, embora os valores executados sejam superiores aos mínimos orientados pelo Custo Aluno-Qualidade Inicial (CAQi) incluída a demanda reprimida. Para os profissionais da educação entrevistados, as limitações para o acesso, para a permanência e para a expansão da El às crianças de 0 a 5 anos se devem à inexistência de uma política de El para o município. Os processos de natureza financeira, gerencial e política dos recursos destinados à El se mostram desarticulados.

\footnotetext{
${ }^{1}$ Mestra em Educação pela Universidade Federal dos Vales do Jequitinhonha e Mucuri. Escritora, Professora da SEE/MG - Secretaria de Estado da Educação e Pedagoga de Teófilo Otoni/MG. Membra da Comissão Articuladora do Fórum Regional de Educação Infantil dos Vales do Mucuri e Jequitinhonha - FREIMJ. ORCID: http://orcid.org/00000002-2189-4002. Email: thaysepinto@hotmail.com

2 Doutorando pelo PPGBIOCOMB - Programa de Pós Graduação em Biocombustíveis da UFVJM - Universidade Federal dos Vales do Jequitinhonha e Mucuri. Mestre em Administração. Docente do PPGED/UFVJM - Programa de Pós Graduação em Educação, Docente do PPGAP/UFVJM - Programa de Pós Graduação em Administração Pública. ORCID: http://orcid.org/0000-0002-3835-9233. Email: professorsimao@ufvjm.edu.br.
} 
Palavras-chave: Educação Infantil. Investimentos na Educação. Teófilo Otoni-MG

\section{THE INVESTMENTS IN CHILHOOD EDUCATION IN TEÓFILO OTONI CITY FROM 2014 TO 2017: AN ANALYSIS IN THE MUCURI VALLEY}

\section{ABSTRACT}

In Brazil, the social movements and social claims were related to the rights achieved by childhood education. Therefore, The Brazilian Federal Constitution (1988) determined that cities should assist and offer childhood education. Even so, the proposal of the Government continues empirical and assistentialist. In this article, investments data in childhood education in the Brazilian city of Teofilo Otoni (in the Mucuri Valley - Minas Gerais State), was analyzed, from 2014 to 2017, through bibliographical, documentary and field researches. In the data of the this program's budget and financial execution of the city, from 2014 to 2017, there are differences between the planning and execution of the values, as well it is clear that the investments made do not meet all the necessary demands - even though they may represent values superior to the minimum investment standards guided by the Initial Quality Student Cost (Custo AlunoQualidade Inicial - CAQi). According to education professionals' perceptions, the limitations and challenges to the access, permanence and expansion to children from 0 to 5 years old is due to nonexistence of public policy for childhood education. The processes of financial, managerial and political for childhood education has been seeing as a challenging issue.

Keywords: Childhood Education. Investments in Education. Teófilo Otoni-MG. 


\section{INVERSIONES EN EDUCACIÓN DE LA PRIMERA INFANCIA DE LA CIUDAD DE TEÓFILO OTONI EN EL PERÍODO 2014/2017: UN ANÁLISIS EM EL VALLE DE MUCURI}

\section{RESUMEN}

En Brasil, los movimientos sociales y las demandas estaban directamente relacionados con los derechos logrados por la educación de la primera infancia. Como consecuencia, la Constitución Federal de Brasil de 1988 determinó que los municipios ofrezcan la educación de la primera infancia. Sin embargo, la administración pública continúa con una postura empírica y asistencialista. En este artículo, se analizaron las inversiones públicas en la primera infancia en el municipio de Teófilo Otoni (en el Valle de Mucuri - Estado de Minas Gerais) de 2014 a 2017, mediante investigaciones bibliográficas, documentales y de campo. En la ejecución financiera, hubo serias discrepancias entre el presupuesto y su ejecución, así como se observó que las inversiones realizadas no satisfacen la demanda, aunque los valores ejecutados son más altos que los valores mínimos orientados por el Costo Inicial de Calidad Estudiantil (Custo Aluno-Qualidade Inicial - CAQi), incluido demanda acumulada. Para los profesionales de la educación, las limitaciones en el acceso, la permanencia y la expansión de la educación de la primera infancia a niños de 0 a 5 años, se deben a la falta de una política para la primera infancia em el municipio. Los procesos financieros, gerenciales y políticos de los recursos destinados a la primera infancia están desarticulados.

Palabras clave: Educación de la Primera Infancia. Inversiones en Educación. Teófilo Otoni-MG.

\section{INTRODUÇÃO}

Na educação básica nacional, a Educação Infantil (EI), que compreende a fase do desenvolvimento humano desde 0 nascimento até os 5 anos de idade, é a primeira etapa que tem como finalidade o processo de construção integral da criança, em 
seus aspectos físico, intelectual e psicossocial, completando a ação da família e da sociedade.

A base histórica dos direitos alcançados pela El demonstrou que os movimentos populares e as inquietações da sociedade em reivindicações sobre a oferta e a ampliação de vagas em creches e pré-escolas tiveram contribuição direta nos direitos alcançados pelas crianças de 0 a 5 anos de idade.

No contexto normativo da El, a Constituição Federal - CF (1988) no $\S 2^{\circ}$ do artigo 211 e a Lei de Diretrizes e Bases da Educação Nacional - LDBEN (1996), no artigo 12, determinaram aos Municípios a oferta do ensino em regime de colaboração com os demais entes federados. Portanto, cabe aos Municípios a garantia do processo educacional na El.

Contudo, nas últimas décadas, a subvinculação de recursos do Fundo de Desenvolvimento e Valorização da Educação Básica e Valorização dos Profissionais da Educação (Fundeb) e sua complementação crescente pela União não têm sido suficientes para a efetivação de uma El abrangente e de qualidade.

A partir do Plano Nacional de Educação - PNE (2014), a União, no que tange à ação supletiva e redistributiva do Sistema Nacional de Educação, estabeleceu metas e estratégias para a El. No entanto, elas não têm sido alcançadas, o que tem provocado debates no campo das políticas públicas de educação quanto ao financiamento, à equalização de oportunidades educativas e aos padrões de qualidade ofertados no atendimento da El. Como consequência, os compromissos políticos firmados na $\mathrm{CF} / 88$ e as limitações de ordem orçamentário-financeira dos Municípios foram colocados em pauta.

Diante disso, o Município de Teófilo Otoni-MG, cidade-polo macrorregional de desenvolvimento, localizada no Vale do Mucuri (nordeste de Minas Gerais), foi definido como cenário desta pesquisa, com o objetivo de se analisar os investimentos realizados pela Prefeitura Municipal - PMTO - na El municipal constantes do seu Plano Plurianual de Investimentos (PPA) aprovado em 2013 cujo período de vigência foi de 2014 a 2017, tendo como objetivos específicos: identificar a execução orçamentária dos valores destinados à $\mathrm{El}$; debater os valores à luz dos parâmetros do Custo 
Aluno-Qualidade Inicial (CAQi); analisar a percepção dos profissionais da educação quanto aos investimentos realizados na El.

A pesquisa foi bibliográfica, documental e de campo, com abordagens qualitativa e quantitativa. Os dados quantitativos foram tratados pela técnica de análise vertical (representatividade) e horizontal (desempenho: evolução/involução), e os dados qualitativos (entrevistas sobre a estrutura e funcionamento da El) foram tratados pela análise do discurso.

\section{A EDUCAÇÃO INFANTIL NA AGENDA NACIONAL}

A garantia dos direitos das crianças de 0 a 5 anos de idade foi conquistada a partir de mobilizações políticas e sociais, que promoveram transformações positivas paulatinamente, em nível nacional, alcançando o reconhecimento do direito educacional da El, num processo de longas lutas desencadeadas pelas reivindicações de movimentos sociais, mulheres operárias, instituições multilaterais e militantes da causa.

Destacaram-se nesse contexto mobilizações sociais, como: Movimento Feminista, Movimento de Luta por Creches, Movimento de Luta nos Bairros, Vilas e Favelas, Movimento dos Trabalhadores Rurais Sem Terra, Movimento Brasileiro de Alfabetização (Mobral), movimentos pela redemocratização do país e movimentos sindicais. Também teve visibilidade, segundo Santos e Sousa Júnior (2017, p. 264), o movimento de fóruns como espaços articuladores e de mobilizações sociais que buscavam $o$ atendimento e 0 discernimento das especificidades da Educação Pré-escolar.

Entre as décadas de 1970 e 1980, o Movimento de Luta por Creches em reivindicação à creche pública e gratuita contribuiu para o aumento da oferta de vagas na Educação Pré-Escolar e somou mais um fato ao processo de inserção da mulher no mercado de trabalho que já vinha se estabelecendo desde o início do século $X X$ (LUCAS 2009, p. 130). Naquele momento, a ênfase era no ensino fundamental e a Educação Pré-escolar tinha pouca relevância no cenário nacional, o que reduzira seu atendimento ao assistencialismo. 
A sistematização da Educação Pré-Escolar em El, no Brasil, como dever do Estado e direito dos cidadãos de 0 a 5 anos de idade, foi estabelecida no artigo 211 da CF/88 em regime de colaboração entre os entes federados. No entanto, a El foi oficialmente reconhecida como a primeira etapa da educação básica a partir da LDBEN (1996).

Em 2009, a Emenda Constitucional $n^{\circ} 59$ reforçou o dever da Federação com a El, incorporando a faixa etária de 4 e 5 anos de idade à gratuidade e à obrigatoriedade da educação básica. Em consonância, o PNE/2014 estabeleceu como proposta para a El a universalização até 2016 da pré-escola e a ampliação da oferta em creches de forma a atender, no mínimo, 50\% das crianças de até 3 anos até o final da vigência do Plano em 2024. Entretanto, essas metas ainda não foram alcançadas e a capacidade do Poder Público de realizar com eficiência a oferta da El ficou exposta. Diante disso, o financiamento da $\mathrm{El}$, em sua perspectiva de ampliação e oferta dessa etapa da educação, entra em debate.

\section{O FINANCIAMENTO DA EDUCAÇÃO INFANTIL}

A CF/88 estabeleceu, na composição de recursos para a educação, que os entes federados atuem em regime de cooperação. A União assumiu a função supletiva e redistributiva dos recursos do Fundeb de 2006 a 2020 - fundo público de natureza contábil que reúne 27 fundos (um por Estado - 26 e o Distrito Federal-DF) constituído de recursos provenientes dos tributos cobrados pelos Estados, DF e Municípios e destinados a este.

Para as transferências do Fundeb, foram estabelecidos fatores de ponderação para cálculo do valor/aluno (Lei $n^{\circ}$ 11.494/2007). Esses fatores devem considerar a correspondência ao custo real da respectiva etapa, modalidade e tipo de estabelecimento da educação básica, de acordo com estudos realizados pelo Instituto Nacional de Estudos e Pesquisas Anísio Teixeira - Inep. Para a El, os valores variam de $\mathrm{R} \$ 0,80$ a $\mathrm{R} \$ 1,30$.

Inobstante à proposta custo-aluno do Fundeb, nos debates para a melhoria da educação no país, surgiu em 2002 o CAQi (Custo Aluno-Qualidade Inicial), como indicador para o cálculo do 
investimento por aluno no Brasil, devido às incoerências produzidas pelo sistema nacional de distribuição de recursos do Fundeb per capita. O CAQi foi divulgado como uma proposta da sociedade civil para a elaboração de padrões mínimos de qualidade para a educação básica. O CAQi obteve reconhecimento no cenário nacional, em destaque pela Campanha Nacional pelo Direito à Educação, que o criou como indicador de qualidade, com os valores mínimos de investimentos na El variando de $R$ \$ 1,50 a $R \$ 2,99$. Embora elencado na Meta 20 do PNE (2014), ainda não foi regulamentado (CAMPANHA NACIONAL PELO DIREITO À EDUCAÇÃO, 2018).

A União promove investimentos por meio dos programas de apoio do FNDE (Fundo Nacional de Desenvolvimento da Educação), por meio de bolsas, auxílios e ações destinadas à formação continuada de profissionais da educação. No Quadro 1, a seguir, encontram-se os programas destinados à El.

Quadro 1 - Programas e Ações do FNDE de Apoio e Financiamento à El (continua)

\begin{tabular}{|l|l|c|}
\hline \multicolumn{1}{|c|}{ Nomenclatura } & \multicolumn{1}{|c|}{ Objetivo } & $\begin{array}{l}\text { Ano de } \\
\text { criação }\end{array}$ \\
\hline $\begin{array}{l}\text { Programa Nacional de } \\
\text { Alimentação Escolar }\end{array}$ & $\begin{array}{l}\text { Oferecer alimentação escolar e ações } \\
\text { de segurança nutricional e alimentar } \\
\text { a todos os alunos que compõem a } \\
\text { educação básica. }\end{array}$ & 1955 \\
\hline $\begin{array}{l}\text { Programa Dinheiro } \\
\text { Direto na Escola } \\
\text { (PDDE) }\end{array}$ & $\begin{array}{l}\text { Oferecer recursos financeiros em } \\
\text { caráter suplementar às escolas } \\
\text { públicas de educação básica em } \\
\text { repasses anuais. }\end{array}$ & 1995 \\
\hline $\begin{array}{l}\text { Programa Nacional } \\
\text { Biblioteca da Escola }\end{array}$ & $\begin{array}{l}\text { Destinar aos alunos e professores } \\
\text { das escolas da educação básica } \\
\text { pública obras didáticas, pedagógicas } \\
\text { eliterárias. }\end{array}$ & 1997 \\
\hline $\begin{array}{l}\text { Programa Nacional de } \\
\text { Apoio ao Transporte } \\
\text { do Escolar }\end{array}$ & $\begin{array}{l}\text { Oferecer recursos financeiros para } \\
\text { despesas de manutenção, impostos, } \\
\text { seguros e licenciamento, taxas, } \\
\text { pneus, combustível. }\end{array}$ & 2004 \\
\hline
\end{tabular}




\begin{tabular}{|c|c|c|}
\hline $\begin{array}{l}\text { Programa de } \\
\text { Formação Inicial para } \\
\text { Professores da El }\end{array}$ & $\begin{array}{l}\text { Ofertar a formação em nível médio à } \\
\text { distância na modalidade normal aos } \\
\text { profissionais que atuam em salas de } \\
\text { aula da El. }\end{array}$ & 2005 \\
\hline $\begin{array}{l}\text { Escola de } \text { Gestores da } \\
\text { Educação } \quad \text { Básica } \\
\text { Pública }\end{array}$ & $\begin{array}{llr}\text { Qualificar gestores, para que } \\
\text { compreendam a proposta de } \\
\text { modelos avançados } & \text { de } \\
\text { gerenciamento de escolas públicas. }\end{array}$ & 2005 \\
\hline $\begin{array}{l}\text { Programa Formação } \\
\text { pela Escola }\end{array}$ & $\begin{array}{l}\text { Ofertar formação continuada para os } \\
\text { profissionais envolvidos na gestão, } \\
\text { controle e prestação de contas e } \\
\text { controle social. }\end{array}$ & 2006 \\
\hline $\begin{array}{ll}\text { Rede Nacional } & \text { de } \\
\text { Formação } & \text { de } \\
\text { Profissionais } & \text { da } \\
\text { Educação - Renafor }\end{array}$ & $\begin{array}{l}\text { Ampliar a parceria com as secretarias } \\
\text { de educação e com instituições } \\
\text { públicas de educação superior para a } \\
\text { formação continuada de professores } \\
\text { da El. }\end{array}$ & 2006 \\
\hline $\begin{array}{l}\text { Programa } \\
\text { Implantação de Salas } \\
\text { de Recursos } \\
\text { Multifuncionais }\end{array}$ & $\begin{array}{l}\text { Oferta e } \quad \text { organização do } \\
\text { atendimento } \\
\text { especializado em salas de recursos } \\
\text { para alunos especiais. }\end{array}$ & 2007 \\
\hline $\begin{array}{l}\text { Reestruturação e } \\
\text { Aquisição de } \\
\text { Equipamentos para } \\
\text { Rede Escolar Pública } \\
\text { de El-Proinfância } \\
\end{array}$ & $\begin{array}{l}\text { Garantir o acesso à escola de } \\
\text { crianças da El, prestando assistência } \\
\text { técnica e financeira aos Municípios. }\end{array}$ & 2007 \\
\hline $\begin{array}{l}\text { Programa Caminho } \\
\text { da Escola }\end{array}$ & $\begin{array}{l}\text { Destinar recursos para a renovação e } \\
\text { ampliação de veículos escolares, da } \\
\text { rede pública de educação básica. }\end{array}$ & 2009 \\
\hline $\begin{array}{l}\text { Programa de Apoio a } \\
\text { Novos } \\
\text { Estabelecimentos de } \\
\text { El }\end{array}$ & $\begin{array}{l}\text { Ampliar a oferta de El com recursos } \\
\text { do Proinfância, para manutenção de } \\
\text { novas turmas em instituições } \\
\text { públicas. }\end{array}$ & 2011 \\
\hline $\begin{array}{l}\text { Programa Brasil } \\
\text { Carinhoso }\end{array}$ & $\begin{array}{l}\text { Segurança nutricional e alimentar e } \\
\text { ações de cuidado integral, em } \\
\text { específico às crianças de zero a } 48 \\
\text { meses. }\end{array}$ & 2012 \\
\hline
\end{tabular}




\begin{tabular}{|c|c|c|}
\hline PDDE Água na Escola & $\begin{array}{l}\text { Recursos financeiros para o } \\
\text { abastecimento de água em } \\
\text { condições para consumo e para fins } \\
\text { de esgotamento sanitário. }\end{array}$ & 2012 \\
\hline $\begin{array}{l}\text { Programa Nacional } \\
\text { do Livro Didático }\end{array}$ & $\begin{array}{l}\text { Destinar aos alunos e professores da } \\
\text { educação básica pública obras } \\
\text { didáticas, pedagógicas e literárias. }\end{array}$ & 2012 \\
\hline $\begin{array}{l}\text { Programa de Apoio a } \\
\text { Novas Turmas de } \\
\text { Educação Infantil }\end{array}$ & $\begin{array}{l}\text { Reduzir o espaço temporal entre o } \\
\text { início das aulas de uma nova turma e } \\
\circ \text { recebimento de recursos do } \\
\text { Fundeb. }\end{array}$ & 2012 \\
\hline PDDE/Escola Acessível & $\begin{array}{l}\text { Oferecer condições de acessibilidade } \\
\text { às escolas públicas. }\end{array}$ & 2013 \\
\hline PDDE/Escola Campo & $\begin{array}{l}\text { Ampliar o acesso e a qualificação da } \\
\text { oferta da educação básica e superior } \\
\text { das redes públicas. }\end{array}$ & 2013 \\
\hline $\begin{array}{l}\text { Formação de Tutores } \\
\text { para as Redes de } \\
\text { Parcerias do FNDE }\end{array}$ & $\begin{array}{l}\text { Capacitar tutores-formadores para os } \\
\text { sistemas públicos de ensino nos } \\
\text { projetos e programas educacionais } \\
\text { do FNDE. }\end{array}$ & 2013 \\
\hline $\begin{array}{l}\text { Programa Nacional } \\
\text { dos Territórios } \\
\text { Etnoeducacionais }\end{array}$ & $\begin{array}{l}\text { Implementação e valorização da } \\
\text { política de educação escolar } \\
\text { indígena, por meio do Plano de } \\
\text { Ações Articuladas (PAR). }\end{array}$ & 2013 \\
\hline $\begin{array}{l}\text { PDDE/Escolas } \\
\text { Sustentáveis }\end{array}$ & $\begin{array}{l}\text { Apoiar ações e investimentos para a } \\
\text { adoção de critérios sustentáveis e } \\
\text { socioambientais nas escolas. }\end{array}$ & 2014 \\
\hline $\begin{array}{lr}\text { Pacto Nacional } & \text { pela } \\
\text { Alfabetização } & \text { na } \\
\text { Idade Certa (El) } & \end{array}$ & $\begin{array}{l}\text { Capacitar professores da El por meio } \\
\text { de parcerias das universidades } \\
\text { públicas com as secretarias de } \\
\text { educação. }\end{array}$ & 2017 \\
\hline
\end{tabular}

Fontes: Fundo Nacional de Desenvolvimento da Educação (2017b)

Os investimentos do Município de Teófilo Otoni com recursos do Fundeb e dos programas de apoio do FNDE, no período de 2014 a 2017 (CÂMARA MUNICIPAL DE TEÓFILO OTONI, 2013), em seus objetivos de promoção da qualidade e da expansão da oferta da El pública, foram analisados neste estudo. 


\section{ANÁLISE E DISCUSSÃO DOS RESULTADOS}

Conforme art. 165 da CF/88, a administração pública municipal deve promover a realização das despesas e investimentos planejados no PPA para seus 4 anos seguintes, ainda que atualizados anualmente na Lei de Diretrizes Orçamentárias (LDO) e na Lei Orçamentária Anual (LOA), inclusive aqueles valores planejados para a El.

\section{Execução Orçamentária dos Investimentos na Educação Infantil}

Foram analisados a representatividade (em cada ano) e o desempenho (ano a ano sucessivamente) dos valores destinados pela $\mathrm{PMTO}$ à El, no período de 2014 a 2017, por meio da técnica de análise vertical e horizontal. Essa técnica reduz todos os valores em percentuais e permite comparar a importância desses valores dentro de um mesmo ano (representatividade percentual), bem como avaliar a variação dos valores em anos sucessivos (desempenho ano a ano) (MATARAZZO, 2010).

Os valores analisados foram extraídos dos balanços orçamentários e financeiros de 2014, 2015, 2016 e 2017 informados pela Prefeitura Municipal de Teófilo Otoni-MG ao Tribunal de Contas do Estado de Minas Gerais (MINAS GERAIS, 2018) e dos balanços anuais de 2014, 2015, 2016 e 2017 disponíveis no site do Sistema de Informações Contábeis e Fiscais do Setor Público Brasileiro - SICONFI - (SECRETARIA DO TESOURO NACIONAL, 2018).

O período de 2014 a 2017 foi selecionado por se tratar do período de planejamento governamental (obrigatório pela $\mathrm{CF} / 88$ ), mais recente no momento de realização da pesquisa, cujos dados encontravam-se acessíveis (VERGARA, 2013) no TCE/MG e na STN. 
Tabela 1 - Análise Vertical dos Investimentos (R\$) da PMTO na El de 2014 a 2017

\begin{tabular}{c|c|c|c|c|c}
\hline \hline Ano & $\begin{array}{c}\text { Previsão } \\
\text { Orçamentária }\end{array}$ & AV & $\begin{array}{c}\text { Despesas } \\
\text { Executadas }\end{array}$ & AV & Diferença \\
\hline 2014 & $19.514 .000,00$ & $35,95 \%$ & $9.419 .644,26$ & $28,31 \%$ & $(10.094 .355,74)$ \\
\hline 2015 & $11.645 .249,00$ & $21,45 \%$ & $9.936 .777,71$ & $29,87 \%$ & $(1.708 .471,29)$ \\
\hline 2016 & $12.899 .440,87$ & $23,76 \%$ & $11.228 .544,06$ & $33,75 \%$ & $(1.670 .896,81)$ \\
\hline 2017 & $10.211 .267,00$ & $18,81 \%$ & $12.100 .038,67$ & $36,37 \%$ & $1.888 .771,67$ \\
\hline Total & $54.269 .956,87$ & $100 \%$ & $42.685 .004,70$ & $100 \%$ & $(11.584 .952,17)$ \\
\hline \hline
\end{tabular}

Fonte: Dados da Pesquisa (2018)

Na Tabela 1, estão calculados os percentuais da previsão orçamentária de cada ano em relação à previsão total para se conhecer a importância dos valores de cada ano em relação ao valor total do período 2014 a 2017, assim como estão calculados os percentuais das despesas executadas de cada ano em relação ao total das despesas executadas do período de 2014 a 2017 (análise vertical). Foi previsto, no PPA 2014/2017 (CÂMARA MUNICIPAL DE TEÓFILO OTONI, 2013), um valor total de investimentos com os programas e com a manutenção da El de $\mathrm{R} \$ 54.269 .956,87$. Todavia, os dados realizados apresentaram $R \$ 42.685 .004,70$. Execução menor em $\mathrm{R} \$ 11.584 .952,17$, com ressalva apenas para o ano de 2017, cuja execução foi superior em $\mathrm{R} \$ 1.888 .771,67$.

Tabela 2 - Análise Horizontal dos investimentos (R\$) realizados PMTO na EI 2014/2017

\begin{tabular}{|l|c|c|c|c|c|c|c|c|}
\hline Ano & 2014 & $\%$ & 2015 & AH & 2016 & AH & 2017 & AH \\
\hline P. O. & $19.514 .000,00$ & 100 & $11.645 .249,00$ & $59,68 \%$ & $12.899 .440,8766,10 \%$ & $10.211 .267,00$ & $52,32 \%$ \\
\hline E. O. & $9.419 .644,26$ & 100 & $9.936 .777,71$ & $5,48 \%$ & $11.228 .544,06$ & $9,20 \%$ & $12.100 .038,67$ & $28,45 \%$ \\
\hline Dif. & $10.094 .355,74$ & & $1.708 .471,29$ & & $1.670 .896,81$ & & $1.888 .771,67$ & $23,87 \%$ \\
\hline
\end{tabular}

Fonte: Dados da Pesquisa (2018) 
Na Tabela 2, estão calculados os percentuais da previsão orçamentária (P. O.) dos anos 2015, 2016 e 2017 em relação à previsão orçamentária (P. O.) de 2014 para se conhecer o desempenho dos valores de cada ano em relação ao ano de 2014, bem como estão calculados os percentuais das execuções orçamentárias (E. O.) dos anos de 2015, 2016 e 2017 em relação à execução orçamentária (E. O.) de 2014 para se conhecer o desempenho dos valores de cada ano em relação a 2014 (análise horizontal).

Embora a execução orçamentária (E. O.) demonstre aumento gradativo de gastos nos quatro anos, de $R \$ 9.419 .644,26$ em 2014 para $\mathrm{R} \$ 12.100 .038,67$ em 2017, distantes do planejado, houve uma redução de $47,68 \%$ na previsão orçamentária (P. O.) com uma diminuição de $R \$ 19.514 .000,00$ (2014) para $R \$ 10.211 .267,00$ (2017). Apenas em 2017 o valor executado foi acima do orçado.

O Quadro 2 apresenta o quantitativo de alunos matriculados nas redes pública e privada de Teófilo Otoni, por faixa etária da El (creche e pré-escola).

Quadro 2 - Quantitativo de crianças matriculadas na El de Teófilo Otoni 2014/2017

\begin{tabular}{|c|c|c|c|c|c|c|}
\hline $\begin{array}{c}\text { Etapa da } \\
\qquad \text { EI }\end{array}$ & $\begin{array}{l}\text { Faixa } \\
\text { etária }\end{array}$ & $\begin{array}{c}\text { Redes } \\
\text { Pública e } \\
\text { privada }\end{array}$ & $\begin{array}{l}\text { Crianças } \\
\text { atendidas } \\
\text { (2014) }\end{array}$ & \begin{tabular}{|c} 
Crianças \\
atendidas \\
$(2015)$
\end{tabular} & $\begin{array}{c}\text { Crianças } \\
\text { atendidas } \\
(2016)\end{array}$ & $\begin{array}{c}\text { Crianças } \\
\text { atendidas } \\
\text { (2017) }\end{array}$ \\
\hline \multirow[t]{2}{*}{ Creche } & \multirow{2}{*}{$\begin{array}{l}0 \text { a } 3 \text { anos } \\
\text { de idade }\end{array}$} & Municipal & 231 & 244 & 237 & 256 \\
\hline & & Particular & 1.295 & 1.381 & 1.449 & 1.478 \\
\hline Subtotal & $\begin{array}{l}0 \text { a } 3 \text { anos } \\
\text { de idade }\end{array}$ & Ambas & 1.526 & 1.625 & 1.686 & 1.734 \\
\hline \multirow[t]{2}{*}{ Pré-escola } & \multirow{2}{*}{$\begin{array}{l}4 \text { e } 5 \text { anos } \\
\text { de idade }\end{array}$} & Municipal & 2.342 & 2.429 & 2.536 & 2.584 \\
\hline & & Particular & 640 & 573 & 612 & 545 \\
\hline Subtotal & $\begin{array}{l}4 \text { e } 5 \text { anos } \\
\text { de idade }\end{array}$ & Ambas & 2.982 & 3.002 & 3.148 & 3.129 \\
\hline Total & $\begin{array}{l}0 \text { a } 5 \text { anos } \\
\text { de idade }\end{array}$ & $\begin{array}{l}\text { Pública e } \\
\text { Privada }\end{array}$ & 4.508 & 4.627 & 4.834 & 4.863 \\
\hline
\end{tabular}

Fonte: Instituto Nacional de Pesquisas e Estudos Educacionais Anísio Teixeira (2018). 
Houve um aumento tímido no atendimento à El como um todo. Em quatro anos, foram acrescidas apenas 355 crianças na El municipal. Dessas, 267 matriculadas na rede pública, sendo 25 até 3 anos de idade e 242 de 4 e 5 anos de idade. A rede municipal de ensino, em 4 anos, apresentou uma média de crescimento anual de 67 crianças atendidas. No atendimento à pré-escola 2016/2017, houve involução de 19 alunos.

Segundo o Inep (2018), 4.863 crianças foram atendidas na El pelo Município (rede pública e rede particular). Esse dado, comparado ao quantitativo de 9.300 crianças de 0 a 4 anos de idade, fornecido pelo IBGE (2018), indica 4.437 crianças sem atendimento na El em Teófilo Otoni. Isso correspondeu a 47,70\% sem acesso. No entanto, não havia informações no Inep e nem no IBGE sobre as crianças de até 5 anos no momento de realização da pesquisa. Se existentes, esse número de 4.437 poderia ser ainda maior.

$\mathrm{Na}$ Tabela 3, constam os valores anuais planejados e executados per capita de 0 a 5 anos de idade no período 2014/2017. Houve redução na previsão orçamentária, crescimento tímido nas despesas executadas, mas aquém aos valores previstos, à exceção do ano de 2017.

Tabela 3 - Investimentos anuais (R\$) per capita para a El em Teófilo Otoni 2014/2017

\begin{tabular}{c|r|r|r|r}
\hline \hline Ano & \multicolumn{1}{|c|}{$\begin{array}{c}\text { Crianças } \\
\text { Atendidas }\end{array}$} & $\begin{array}{c}\text { Previsão } \\
\text { Orçamentária }\end{array}$ & $\begin{array}{c}\text { Despesas } \\
\text { Executadas }\end{array}$ & Diferença \\
\hline 2014 & 2.573 & $7.584,14$ & $3.660,96$ & $(3.923,18)$ \\
\hline 2015 & 2.673 & $4.356,62$ & $3.717,46$ & $(639,15)$ \\
\hline 2016 & 2.773 & $4.651,79$ & $4.049,24$ & $(602,55)$ \\
\hline 2017 & 2.840 & $3.595,51$ & $4.260,58$ & $\$ 665,06$ \\
\hline Total $^{3}$ & 10.859 & $20.188,06$ & $15.688,24$ & $(4.499,82)$ \\
\hline \hline
\end{tabular}

Fonte: Dados da Pesquisa (2018)

${ }^{3}$ Esse quantitativo não pode ser considerado fator evolutivo, pois parte dos alunos permanece na El de um ano para o outro. 
Na Tabela 4, há o investimento per capita ao dia pelos valores do PPA 2014-2017, considerando o mínimo anual de 200 dias letivos na educação básica (LDBEN, 1996).

Tabela 4 - Investimento diário (R\$) per capita para a El em Teófilo Otoni 2014/2017

\begin{tabular}{c|r|r|r}
\hline \hline Ano & \multicolumn{1}{|c|}{$\begin{array}{c}\text { Previsão } \\
\text { Orçamentária }\end{array}$} & $\begin{array}{c}\text { Despesas } \\
\text { Executadas }\end{array}$ & \multicolumn{1}{c}{ Diferença } \\
\hline 2014 & 37,90 & 18,30 & $(19,62)$ \\
\hline 2015 & 21,80 & 18,59 & $(3,20)$ \\
\hline 2016 & 23,30 & 20,25 & $(3,01)$ \\
\hline 2017 & 18,00 & 21,30 & 3,30 \\
\hline \hline
\end{tabular}

Fonte: Dados da Pesquisa (2018)

O gasto com aluno da El por dia está acima dos valores destinados pelo Fundeb e acima daqueles considerados mínimos pelo CAQi, apesar da redução significativa entre a previsão e a execução.

Diante do aumento tímido na ampliação da El em Teófilo Otoni (Quadro 2), na seção seguinte, apresenta-se uma estimativa de investimentos sob os valores do CAQi, para o atendimento da demanda reprimida e da atendida da El.

\section{A Demanda Reprimida nos parâmetros de investimento do CAQi}

Diante da proposta do CAQi na elaboração de padrões mínimos de qualidade para a El, foram realizadas simulações para o atendimento da demanda atendida e reprimida do município de Teófilo Otoni. A Tabela 5 apresenta as diferenças dos valores desejáveis pelo CAQi para investimentos per capita por dia na El e os valores repassados pelo Fundeb. 
Tabela 5 - Diferença dos valores (R\$) da EI - CAQi (desejável) X Fundeb (real)

\begin{tabular}{l|c|c|c}
\hline \hline \multicolumn{1}{c|}{ Etapa/Modalidade } & $\begin{array}{c}\text { CAQi mínimo } \\
\text { desejável }\end{array}$ & $\begin{array}{c}\text { Fundeb } \\
\text { real }\end{array}$ & Diferença \\
\hline \hline Creche pública em tempo integral & 2,99 & 1,30 & 1,69 \\
\hline Creche pública em tempo parcial & 2,99 & 1,00 & 1,99 \\
\hline $\begin{array}{l}\text { Creches conveniadas em tempo } \\
\text { integral }\end{array}$ & 2,99 & 1,10 & 1,89 \\
\hline $\begin{array}{l}\text { Creches conveniadas em tempo } \\
\text { parcial }\end{array}$ & 2,99 & 0,80 & 2,19 \\
\hline $\begin{array}{l}\text { Pré-escola em tempo integral } \\
\text { Pré-escola em tempo parcial }\end{array}$ & 1,50 & 1,30 & 0,20 \\
\hline Total da diferença per capita na El & 1,50 & 1,00 & 0,50 \\
\hline
\end{tabular}

Fontes: Campanha Nacional pelo Direito À Educação (2015); Brasil (2007, 2016).

A partir dos dados acima, foi possível realizar outras duas análises: pela demanda atendida e pela demanda reprimida de Teófilo Otoni. A primeira análise considerou o quantitativo de alunos da El atendidos (INEP, 2018), exposto no Quadro 2, o índice sugerido de investimento mais elevado do CAQi ( $R$ 2,99 per capita/dia (Tabela 5) e o mínimo de dias letivos no calendário da educação básica (LDBEN, 1996). A partir desses dados, calculou-se o valor sugerido per capita pelo CAQi, para atendimento à demanda atendida da El de 2017. A segunda análise considerou a demanda reprimida exposta pela projeção do IBGE (2017), os 200 dias letivos (BRASIL, 1996) e o parâmetro máximo de referência per capita do CAQi, para atendimento à demanda reprimida da El em 2017.

A Figura 1 apresenta a primeira análise, considerando a demanda atendida pela rede pública de Teófilo Otoni (creche e préescola). 
Figura 1 - Base de referência para cálculo da demanda atendida por parâmetros do CAQi

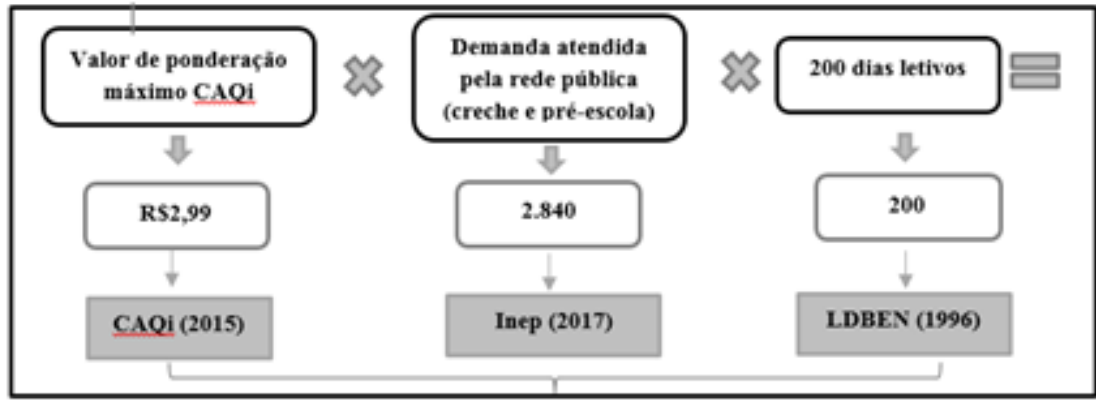

Fonte: Dados da Pesquisa (2018)

Foi considerada a fórmula de cálculo: [R \$2,99 (CAQi) X DEMANDA ATENDIDA (INEP, 2018) X 200 (DIAS LETIVOS)]. O resultado foi de $R \$ 1.698 .320,00$ para atender aos 2.840 alunos informados pelo Inep (2018). Entretanto, a execução orçamentária municipal (Tabela 1) demonstrou um valor gasto de $\mathrm{R} \$ 12.100 .038,67$. Portanto, financeiramente, seria possível ter atendido à demanda reprimida da El de Teófilo Otoni, em 2017, diante da considerável distância entre o valor mínimo per capita sugerido pelo CAQi e o gasto realizado com o aluno da El em 2017.

$\mathrm{Na}$ segunda análise, da demanda reprimida da El, foi utilizada fórmula similar à Figura 1: [R $\$ 2,99$ (CAQi) $X$ demanda reprimida (IBGE, 2017 - 0 a 4 anos de idade); Inep (2017) X 200 (dias letivos)].

Figura 2 - Base de referência para cálculo da demanda reprimida, de acordo com o CAQi

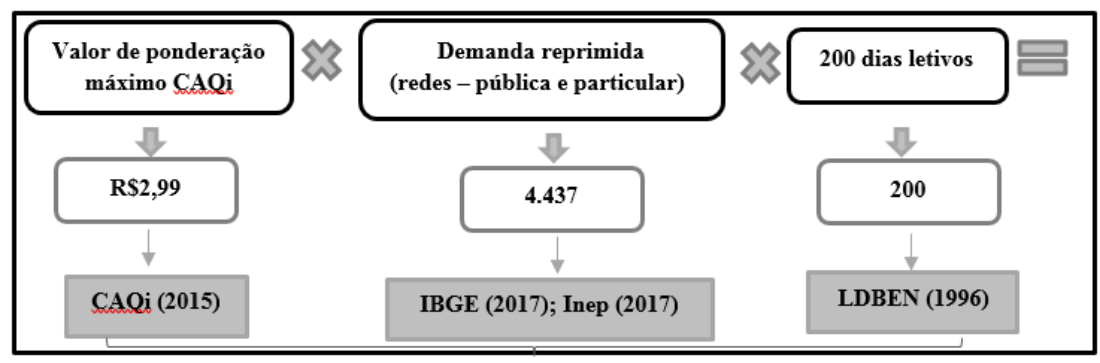

Fonte: Dados da Pesquisa (2018)

Considerando os parâmetros do CAQi, houve recursos para atendimento a toda a população da El em 2017, bastando pouco 
mais de $1 / 3$ dos recursos destinados à El. Em valores absolutos, um acréscimo de $R \$ 2.653 .326,00$. Isso pode ser observado na soma dos valores da demanda atendida adicionada à demanda reprimida.

Sob essa análise, seria possível, com $\mathrm{R} \$ 4.351 .646,00$, atender a todos os alunos da El. Para outros fins, ainda restariam R\$7.748.392,67, considerando a execução orçamentária. O distanciamento financeiro entre o que foi e o que poderia ser atendido com menos recursos tem relevo.

Para melhor análise desses resultados, foram realizadas entrevistas com 10 profissionais da secretaria municipal de educação (7 pedagogas e 3 técnicos) lotados na El municipal e com a presidente do FREIMJ (Fórum Regional de Educação Infantil dos Vales do Mucuri e Jequitinhonha). As entrevistas foram autorizadas pelo CEP/UFVJM - Comitê de Ética em Pesquisa da Universidade Federal dos Vales do Jequitinhonha e Mucuri - por meio de análise do projeto da pesquisa e emissão do parecer 3.335 .212 de 28/05/2019, no qual consta a necessidade de preservar o anonimato dos respondentes.

Os entrevistados e as entrevistadas podem ser classificados em três grupos distintos e uma entrevistada individual:

Grupo 1: quatro pedagogas efetivas do Núcleo de Educação Infantil que convivem com a realidade das escolas da El municipal, exercem atividades de assessoramento pedagógico, como mediadoras das atividades de planejamento, construção, execução e avaliação do Projeto Político Pedagógico, realizam visitas in loco e plantões pedagógicos; Grupo 2: quatro servidores do setor de prestação de contas, todos efetivos atuando diretamente no acompanhamento dos programas de financiamento da educação infantil (duas pedagogas); Grupo 3: dois servidores da assessoria (uma em cargo efetivo - pedagoga - e um em cargo comissionado) que auxiliam nos processos de gestão dos programas que financiam a El no município; a representante do FREIMJ (servidora pública federal e pedagoga) que atua há 25 anos no acompanhamento das políticas públicas da $\mathrm{El}$ e no enfrentamento aos desafios à promoção dos direitos das crianças de 0 a 5 anos de idade, na região dos vales do Mucuri e Jequitinhonha. 


\section{A El de Teófilo Otoni na Percepção dos Profissionais da Educação Municipal}

Para as pedagogas entrevistadas que atuaram na El no período 2014/2017, o financiamento da El em Teófilo Otoni não atendeu quantitativamente à demanda reprimida e sequer qualitativamente os matriculados. Houve a ausência de fatores determinantes nos processos de gestão, que impossibilitaram ações de melhorias.

O Gráfico 1 mostra a falta de planejamento como fator determinante no atendimento à demanda reprimida. Para os onze entrevistados, faltou interesse do Poder Público no atendimento qualitativo à El e na construção de novos espaços físicos. Os entrevistados (E1, E2, E3, E4 e E11) pontuaram que faltou o reconhecimento da El como primeira etapa da educação básica e a compreensão das especificidades de cada faixa da EI. E1, E2, E3 e E4 sinalizaram que houve ausência da reestruturação de espaços existentes e que o atendimento foi voltado para o assistencialismo em instituições filantrópicas.

Gráfico 1 - Fatores impeditivos ao atendimento qualitativo da El de Teófilo Otoni-1

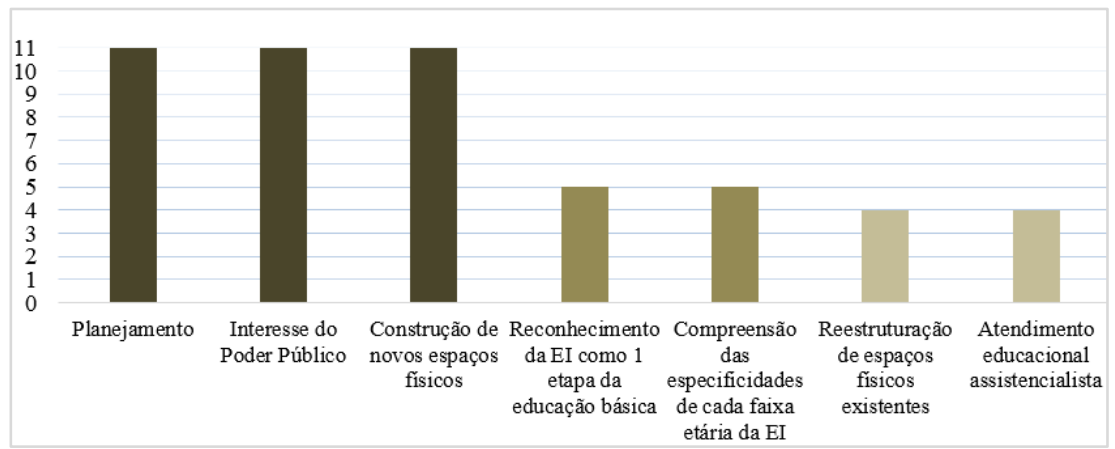

Fonte: Dados da Pesquisa (2019)

Os entrevistados (E1, E2, E3 e E4) evidenciaram uma parceria municipal com entidades filantrópicas, na busca de atender à demanda crescente da El e responder à obrigatoriedade da oferta presente na Meta 1 do PNE/2014. O entrevistado (E11) sinalizou que Teófilo Otoni foi tardio no movimento de atender à demanda 
reprimida, porque "[...] não conhecia a sua própria rede. Desse modo, - Município entendia que as creches conveniadas iriam sempre atender as crianças de 0 a 3 anos de idade".

De acordo com os entrevistados (E1, E2, E3 e E4), as instituições filantrópicas ainda são voltadas para práticas assistencialistas na El, apesar de receberem as mesmas condições de materiais didáticos, alimentação e professores dos demais educandários para manutenção e desenvolvimento do ensino na pré-escola. $E$, em algumas delas, há inclusive melhor infraestrutura que em outras escolas municipais. Diante disso, quando (E1, E2, E3 e E4) foram questionados sobre os indicadores que foram adotados para aferir o acesso, a permanência e o desempenho/qualidade da $\mathrm{El}$, a resposta foi a mesma: "Eu desconheço. Não há!".

Em relação à unificação das respostas, Bakhtin (2016, p. 4950) sinalizou que, na comunicação discursiva, há tipos bastante padronizados. Portanto, a entonação expressiva pertence ao enunciado e não às palavras. Nesse caso, a expressividade na dialogia de E1, E2, E3 e E4 demonstrou precisão nas afirmações.

Nesse contexto, três dos quatro entrevistados (E1, E2, E3 e E4), quando questionados sobre a proposta do CAQi, apontaram desconhecer. Entretanto, o entrevistado (E1) sinalizou que "[...] os quesitos básicos para atendimento da educação infantil com qualidade são deficitários em Teófilo Otoni. Sendo assim faltam nas escolas: infraestrutura e materiais didáticos adequados; qualidade na merenda escolar". O respondente $\left(E_{1}\right)$ entende que o Município "[...] não levou em consideração os parâmetros mínimos do CAQi, ou pelo menos essa é a impressão que passa".

Houve convergência entre as opiniões de todos os respondentes em relação ao acesso, à permanência e à elevação da qualidade. Todos afirmaram que a ampliação que vem ocorrendo em Teófilo Otoni é uma atitude forçada, impulsionada pelo Ministério Público, que vem cobrando cumprimento constitucional do atendimento à El.

Para os entrevistados E1, E2, E3, E4, E5, E6, E7 E8, E9 e E11, não houve um planejamento, uma proposta de Governo ou de política pública para a $\mathrm{El}$, mas sim o cumprimento de uma exigência legal. Diante disso, E11 relatou que "a ampliação da educação 
infantil de Teófilo Otoni não converge como uma política pública, ela tem uma obrigatoriedade da legislação a cumprir [...]". O E11 pontuou que "é uma política de arranjos, que se organiza para atender a legislação, mas não pensa e não atende os direitos prioritários dessa infância".

O entrevistado (E11) ainda sinalizou que, desde as primeiras tentativas de ampliação da El em Teófilo Otoni, o processo foi muito lento, sem um estudo da demanda local e de sua rede para atendimento, faltou uma estrutura de planejamento. Em relação à Meta 1 e às Estratégias do PNE/2014 para a El, constantes no PME (Plano Municipal de Educação de Teófilo Otoni/2015): "Universalizar até 2016 a El na pré-escola para as crianças de 4 (quatro) a 5 (cinco) anos de idade e ampliar sua oferta em creches de forma a atender, no mínimo, 50\% das crianças de até 3 (três) anos até o final da vigência do PNE", a entrevistada E1 expôs que a Meta 1 do PNE estava sendo tentada e que, das 17 estratégias do PNE, pelo menos 11 são atendidas com limitações no PME do município. Contudo, tanto na efetivação das metas do PNE quanto nas do PME, houve falhas nos processos de gestão para o alcance de ambas.

A maioria dos servidores da Secretaria Municipal de Educação, Ciência e Tecnologia (SMECT) e a representante do FREIMJ pontuaram que não foi constatado um esforço nos processos de gestão para alcance das definições de ambos os Planos - PNE/2014 e PME de Teófilo Otoni/2015. Muito embora o cumprimento das metas do PNE não seja uma opção, mas uma determinação legal que não vem sendo cumprida pelo Município.

A condução coesa da SMECT nos processos estruturais da EI é essencial para o funcionamento e o direcionamento da política local de atendimento à El. A oferta ou a limitação de vagas em creches e pré-escolas depende diretamente da gestão dos recursos destinados à El.

Diante disso, os entrevistados (E5, E6, E7 e E8) responderam do ponto de vista técnico sobre a Estrutura Básica de Funcionamento da El de Teófilo Otoni. Para a captação e análise das respostas, foi utilizada a mensuração de satisfação, por meio da escala de Likert (SILVA JUNIOR; COSTA, 2014). 
Gráfico 2 - Estrutura Básica de Funcionamento da El

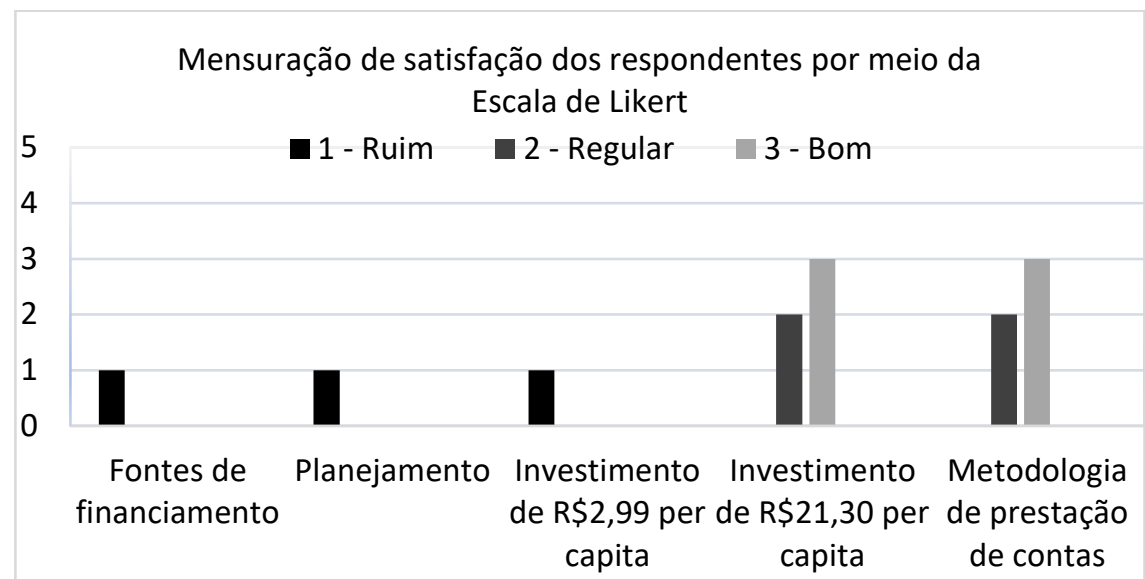

Fonte: Dados da Pesquisa (2019)

Pelo Gráfico 2, os entrevistados ( $E_{5}, E_{6}, E_{7}$ e $\left.E_{8}\right)$ classificaram como ruim: as fontes de financiamento da El, o planejamento dos fatores físicos, pedagógicos e tecnológicos e materiais na determinação dos valores para investimentos na El, o investimento proposto pelo CAQi de $\mathrm{R} \$ 2,99$ por dia per capita na El. A Campanha Nacional pelo Direito à Educação recomendou o valor de $\mathrm{R} \$ 2,99$ por dia per capita, como um valor que pode prover insumos para 0 atendimento à El, com um mínimo de qualidade.

Sobre a proposta do CAQi em relação ao gasto por aluno na $\mathrm{El}$, o entrevistado $\left(\mathrm{E}_{8}\right)$ sinalizou que: "Não temos dados para mensurar isso [...]". O respondente $\left(\mathrm{E}_{7}\right)$ pontuou que "os nossos gestores não vão saber o que significa CAQi. Nunca se conversou educação a partir de um planejamento orçamentário, para se discutir isso. Então, nem o CAQi sem o I, ou seja, Quanto Custa o nosso aluno?" e o $\mathrm{E}_{7}$ ainda informou que "começa-se uma gestão de 4 anos ou um ano orçamentário, sem se ter ideia do quanto custa o aluno".

Percebe-se a ausência de planejamento e de articulação setorial, pois não houve instrumentos para pensar o aluno da $\mathrm{El}$, no contexto das ações do governo municipal. Principalmente porque, no contexto do financiamento da El, gastou-se (de acordo com a Tabela 4), R\$21,30 por dia, em valores per capita na El em 2017. Se não houve planejamento para os gastos, esse valor foi executado 
sem previsão, fora de uma projeção orçamentária e análise dos seus resultados.

$\mathrm{Na}$ opinião do entrevistado $\left(\mathrm{E}_{7}\right)$, "nunca houve, na prestação de contas, uma metodologia específica para a El. A única prestação que foi e é específica é a do Programa de Apoio a Novas Turmas de Educação Infantil, transferência por meio do Fundeb". Os respondentes ( $E_{5}$ e $\left.E_{7}\right)$ concordaram com a afirmação.

Pela análise dos dados da Metodologia de Prestação de Contas da SMECT por $E_{5}, E_{6}, E_{7}$ e $E_{8}$, faltou transparência pública nos processos de prestação de contas. Afirmação que pode ser corroborada quando o respondente $\left(\mathrm{E}_{7}\right)$ afirma que "a SMECT somente sabe o quanto que a educação gasta por ano, porque deve informar, para cumprir a meta de $25 \%$ constitucional", e o respondente $\mathrm{E}_{8}$ sinaliza que "ao contrário disso, talvez nem essa conta de quanto a SMECT utilizou no ano, saberiam responder, se questionados". O entrevistado $\left(\mathrm{E}_{8}\right)$ pontuou o ato de prestar contas como o cumprimento de um preceito legal.

Como perspectiva, é apresentada, no Gráfico 3, a contribuição dos técnicos para futuras ações de melhoria da El local, levando em consideração as dificuldades elencadas no atendimento às demandas da El.

Gráfico 3 - Fatores que podem contribuir nos Investimentos para a El de

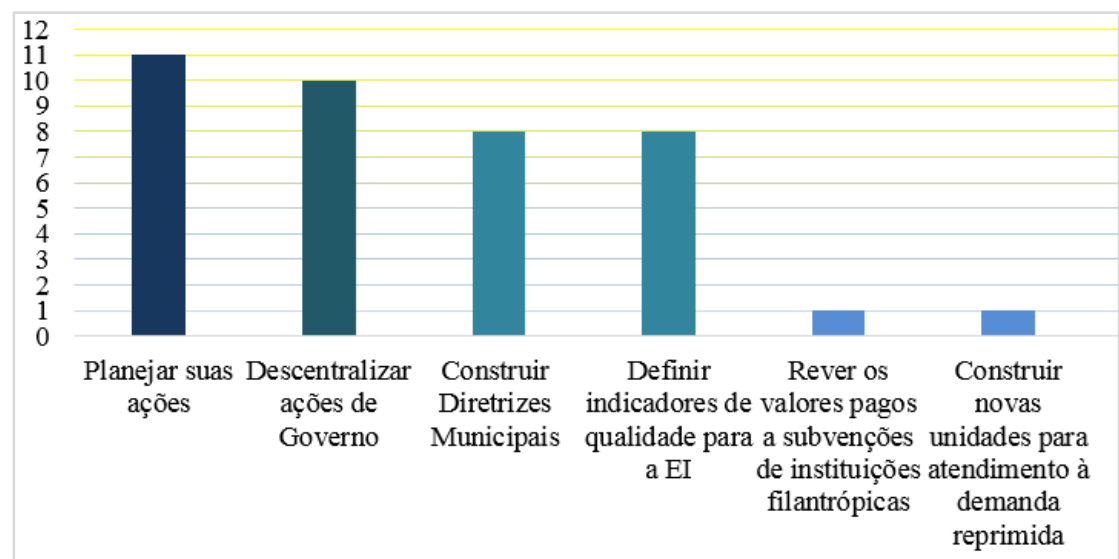

Fonte: Dados da Pesquisa (2019) 
O Gráfico 3 mostra que os 11 entrevistados (E1, E2, E3, E4, E5, E6, E7, E8, E9, E10 e E11) sinalizaram o planejamento como fator estratégico que deve ser repensado pelo Município na construção de suas ações. Para o atendimento à demanda da El, atos de planejamento e descentralização de ações, por meio de parcerias intersetoriais com servidores da El e com a sociedade civil, foram sinalizados como forma de melhoria do processo. Contudo, para o alcance dessas ações, "falta a promoção de debates dentro da rede SMECT, com seus profissionais, para que cada setor exponha suas inquietações e contribua com ações para melhoria da educação infantil local, para além das já elencadas" (E11).

Nesse contexto, o representante do FREIMJ (E11) citou o apostilamento4 da educação infantil, introduzido pela Gestão Municipal de Teófilo Otoni, em 2017. Essa decisão não foi participativa e não escutou os especialistas em El e/ou o Freimj, e introduziu nas escolas um material, sem compreender a realidade local e as necessidades da El. O FREIMJ sinalizou que essa ação era contraditória a tudo que vinha sendo discutido em prol da El e alertou a sociedade em movimentos e reuniões. Como parte da justificativa para isso, o entrevistado E9 sinalizou que o fluxo de origens e de aplicações dos recursos planejados para a $\mathrm{El}$, no período de análise (2014/2017), foi gerenciado pela PMTO sem participação da SMECT. Diante disso, o entrevistado (E2) sinalizou que: "Nós precisamos de um gestor, na Secretaria de Educação, ou no Município, que tenha condição de entender e valorizar a educação infantil [...]". Cabe observar que a compreensão da El como política pública de direito e sua valorização não devem estar associadas às ações vinculadas a gabinetes de gestão, pois a CF/88 e as Leis que regem a educação já definiram essa prerrogativa aos gestores educacionais. $\mathrm{O}$ argumento do entrevistado reforça o entendimento de Fairclough (2001, p. 30). Percebe-se um vínculo social historicamente construído de dependência subjetiva e não de expectativa objetivamente determinada pelas instituições e suas

\footnotetext{
${ }^{4}$ Apostilamento - no Município, em 2017, foram implantados materiais pedagógicos apostilados de uma editora nacional para as crianças da educação infantil.
} 
normas. Sua palavra está diretamente condicionada às práticas sociais e aos vícios delas derivados.

Para compreensão das liberações financeiras dos programas de apoio e financiamento do FNDE, foram pesquisados, no SIGEFWEB/Siafi ${ }^{5}$, os valores destinados pelo FNDE à El de Teófilo Otoni, no período 2014 a 2017. No sistema de informações do PDDE e de suas ações agregadas - PDDEREx (BRASIL. 2017a), foram consultadas as liberações do FNDE (BRASIL, 2017b) para o Município. Sobre apoios externos à $E l$, restringe-se às ações do FNDE, cujos programas acolhidos pelo município no período 2014/2017 encontram-se no Quadro 2.

O Quadro 3 apresenta os 13 programas do FNDE que foram aderidos pelo município no período 2014/2017, dos 22 existentes (Quadro 2) com a participação direta de E1, E2, E3, E4 e E10. Outros não foram alcançados por desconhecimento da Gestão Municipal (E10). Ressalta-se que, em 2014, o município foi contemplado com a possibilidade de usar 9 milhões de reais do Programa PROINFÂNCIA para a construção de 6 unidades escolares de El. Entretanto, devido a questões burocráticas não resolvidas, não as construiu e não executou esses recursos previstos no PPA 2014/2017.

Quadro 3 - Programas do FNDE desenvolvidos em Teófilo Otoni 2014/2017

\begin{tabular}{|l|c|}
\hline \multicolumn{1}{|c|}{ Programas que destinaram recursos a El } & 2014/2017 \\
\hline Programa Brasil Carinhoso & $\mathrm{X}$ \\
\hline Programa Caminho da Escola & $\mathrm{X}$ \\
\hline Programa Formação pela Escola & $\mathrm{X}$ \\
\hline $\begin{array}{l}\text { Programa Nacional de Reestruturação e Aquisição de } \\
\text { Equipamentos para Rede Escolar Pública de Educação } \\
\text { Infantil (Proinfância) }\end{array}$ & $\mathrm{X}$ \\
\hline Programa Dinheiro Direto na Escola (PDDE) & $\mathrm{X}$ \\
\hline PDDE/Escola Acessível & \\
\hline
\end{tabular}

5 Sistema Integrado de Gestão Financeira (SIGEFWEB), realiza repasses financeiros no Sistema Integrado de Administração Financeira (Siafi) para os Municípios (BRASIL, 2017b). 


\begin{tabular}{|l|c|}
\hline Programa Nacional de Alimentação Escolar & $X$ \\
\hline Programa Nacional de Apoio ao Transporte Escolar & $X$ \\
\hline Programa Nacional do Livro Didático & $X$ \\
\hline Programa Nacional Biblioteca da Escola & $X$ \\
\hline Pacto Nacional pela Alfabetização na Idade Certa (EI) & $X$ \\
\hline $\begin{array}{l}\text { Programa de Formação de Tutores para as Redes de } \\
\text { Parcerias do FNDE }\end{array}$ & $X$ \\
\hline Programa de Apoio a Novas Turmas de Educação Infantil & $X$ \\
\hline
\end{tabular}

Fonte: https://www.fnde.gov.br/sigefweb/index.php/liberacoes (2014/2017);

Dados da Pesquisa (2019).

De acordo com o entrevistado E10, a avaliação do investimento per capita na El e o acompanhamento dos recursos aplicados ocorrem por meio de relatórios contábeis. Todavia, os respondentes (E5, E6, E7 e E8) informaram não saber quanto custou e/ou quanto custa o aluno da El. Cabe ressaltar que a vivência de cada participante influencia sua análise e seu julgamento em relação ao perguntado. Bakhtin 1895-1975 (2016) sinalizou que o tato discursivo na conversação cotidiana transfere peculiaridades nos estilos falados. Para Fairclough (2001) o discurso é moldado e construído a partir das relações sociais vividas.

Sobre os critérios utilizados para a destinação de recursos do Fundeb à $\mathrm{El}$, os entrevistados $\left(\mathrm{E}_{9}\right.$ e $\left.\mathrm{E}_{10}\right)$ responderam que $60 \%$ do total dos recursos do Fundeb para a educação são destinados à folha de pagamento dos servidores, os outros $40 \%$ do total dos recursos do Fundeb são utilizados no apoio às instituições filantrópicas que atendem à El. Segundo o entrevistado ( $\left.E_{10}\right)$, "OS recursos do Fundeb não têm além para fazer investimentos. A prioridade é a folha de pagamento".

$\mathrm{Na}$ efetivação da oferta da El no contexto analisado, verificou-se, nas ações do governo, a preocupação com a oferta de vagas para o cumprimento legal. O problema é que, se essa etapa de escolarização não for vivenciada nos primeiros cinco anos de vida, não poderá ser mais. A oportunidade dessa etapa não se repetirá. 


\section{CONSIDERAÇÕES FINAIS}

No contexto analisado, a administração pública insiste num modelo de gestão sem indicadores mínimos do custo-aluno na complexidade da $\mathrm{El}$, reduzindo os parâmetros do CAQi nas estratégias da Meta 20 do PNE para 2016.

A situação de não priorização da El no Brasil é percebida no período de 2014/2017 em Teófilo Otoni. A política municipal, na distribuição de recursos arrecadados e no controle da qualidade de insumos mínimos necessários ao processo de ensino-aprendizagem da El, foi insensível às especificidades da El.

Houve dificuldades gerenciais em atender às demandas da El. Para suavizar essas dificuldades, parcerias com entidades filantrópicas foram realizadas e a herança assistencialista foi mantida. Como consequência, foram assumidos compromissos sem discutir a qualidade e as especificidades da El. Nesse aspecto, as formas congêneres de parcerias sem planejamento e parâmetros refletiram nos motivos do baixo acesso à El. Foi identificado um modelo paliativo de gestão, que estruturou suas ações para atender às crianças da El sob exigência legal.

Entre o valor sugerido pelo CAQi e o executado na El, aprofundam-se as dúvidas de natureza gerencial, financeira e política sobre o atendimento da demanda reprimida, pois o problema não foi recurso financeiro. $E$, nessa distância entre o gasto desejável per capita (CAQi) e a realidade vivenciada na execução orçamentária, crianças da El ficaram sem atendimento.

Sobre as ações de planejamento, faltou a construção de propostas estratégicas conjuntas, sob enfoques intersetorias, com envolvimento de todos os segmentos, que acompanham a El. Isso porque o Município demonstrou não conhecer a rede de ensino que atende, não possuiu diretrizes operacionais para delinear sua trajetória político-pedagógica e não construiu um planejamento com a participação dos envolvidos na El.

Ademais, no período analisado, o Município não construiu suas ações por meio do fornecimento de informações acessíveis, no que tange à transparência dos seus atos de governo. O PPA de 2014 
a 2017 relacionou em seu texto informações soltas que não deram ligação entre demandas da El e ações governamentais específicas.

Diante disso, a El, no contexto pesquisado, ainda reclama suas políticas públicas próprias e demonstra que há grandes desafios a superar, desde a leitura da demanda real à garantia do seu acesso e permanência, o fornecimento de infraestrutura física adequada às escolas, a construção de novos estabelecimentos para a El, o acompanhamento dos processos pedagógicos das escolas (públicas, particulares, filantrópicas e/ou confessionais) e o alinhamento financeiro de uma proposta a ser construída para a El.

Considera-se, por fim, que os dados deste estudo reforçam a pertinência das políticas afirmativas para a El, tendo em vista as limitações da sua compreensão e a necessidade da sua validação nos processos de gestão e de planejamento no contexto encontrado. Destacam, também, a ausência de discussões básicas para sua estruturação e seu financiamento como política educacional muito além do caráter assistencialista que a reduz.

\section{REFERÊNCIAS}

BAKHTIN, M. Os gêneros do discurso. Organização, tradução, posfácio e notas: Paulo Bezerra. Notas e edição russa: Serguei Botcharov. São Paulo: Editora 34, 2016.

BRASIL Emenda Constitucional no 59, de 11 de novembro de 2009. Acrescenta $\S 3^{\circ}$ ao art. 76 do Ato das Disposições Constitucionais Transitórias para reduzir, anualmente, a partir do exercício de 2009, o percentual da Desvinculação das Receitas da União incidente sobre os recursos destinados à manutenção e desenvolvimento do ensino de que trata o art. 212 da Constituição Federal, dá nova redação aos incisos I e VII do art. 208, de forma a prever a obrigatoriedade do ensino de quatro a dezessete anos e ampliar a abrangência dos programas suplementares para todas as etapas da educação básica, e dá nova redação ao $\S 4^{\circ}$ do art. 211 e ao $\S 3^{\circ}$ do art. 212 e ao caput do art. 214, com a inserção neste dispositivo de inciso VI. Diário Oficial da União: Brasília, DF, 12 nov. 1996.

Disponível em: 
http://www.planalto.gov.br/ccivil_03/constituicao/emendas/emc/em c59.htm. Acesso em: 14 fev. 2018.

BRASIL Fundo Nacional de Desenvolvimento da Educação.

PDDEREx: Sistema PDDEREx. Brasília, 2017a. Disponível em:

https://www.fnde.gov.br/fnde_sistemas/pdderex. Acesso em: 01 jun. 2019.

BRASIL Fundo Nacional de Desenvolvimento da Educação:

Liberações. Brasília, 2017b. Disponível em:

https://www.fnde.gov.br/sigefweb/index.php/liberacoes. Acesso em: 03 jun. 2019.

BRASIL Fundo Nacional de Desenvolvimento da Educação.

Resolução MEC n 1, de 28 de julho de 2016. Aprova as

ponderações aplicáveis entre diferentes etapas, modalidades e tipos de ensino da educação básica, para 2017. Brasília, 2016. Disponível em: https://www.fnde.gov.br/resolucoes/resolucoes-2016. Acesso em: 05 ago. 2017.

BRASIL Lei no 11.494, de 20 de junho de 2007. Regulamenta o Fundo de Manutenção e Desenvolvimento da Educação Básica e de Valorização dos Profissionais da Educação - FUNDEB, de que trata o art. 60 do Ato das Disposições Constitucionais Transitórias; altera a Lei $\mathrm{n}$ o 10.195, de 14 de fevereiro de 2001; revoga dispositivos das Leis n os 9.424, de 24 de dezembro de 1996, 10.880, de 9 de junho de 2004, e 10.845, de 5 de março de 2004; e dá outras providências. Diário Oficial da União: Brasília, DF, 21 jun. 2007.

BRASIL Ministério da Educação. Lei de Diretrizes e Bases da Educação Nacional, Lei no 9.394, de 20 de dezembro de 1996. Estabelece as diretrizes e bases da educação nacional. Diário Oficial da União: Brasília, DF, 23 dez. 1996. Disponível em: http://www.planalto.gov.br/ccivil_03/leis/L9394.htm. Acesso em: 08 jan. 2017.

BRASIL Ministério da Educação. Lei 13.005 de 25 de junho de 2014. Aprova o Plano Nacional de Educação - PNE e dá outras providências. Diário Oficial da União: Brasília, DF, 26 jun. 2014. 
Disponível em: http://www.planalto.gov.br/ccivil_03/_ato20112014/2014/lei/l13005.htm. Acesso em: 12. out. 2018.

BRASIL. Constituição Federal. Constituição da República

Federativa do Brasil 1988. Brasília, Senado Federal, 1988.

CAMPANHA NACIONAL PELO DIREITO À EDUCAÇÃO. Custo AlunoQualidade Inicial. 2015. Disponível em:

http://www.custoalunoqualidade.org.br/. Acesso em: 12 fev. 2018.

FAIRCLHOUGH, N. Discurso e mudança social. Tradução: Izabel

Magalhães. Brasília: Universidade de Brasília, 2001.

IBGE. Instituto Brasileiro de Geografia e Estatística. Panorama 2018.

Disponível em: https://cidades.ibge.gov.br/brasil/mg/teofilo-

otoni/panorama. Acesso em: 30 mar. 2018.

INEP. Instituto Nacional de Pesquisas e Estudos Educacionais Anísio Teixeira. Sinopse Estatística de Educação Básica 2017. Brasília: Inep, 2018. Disponível em: http://portallnep.govbr/sinopsesestatísticas-da-educação-básica. Acesso em 24 ago. 2018.

LUCAS, M. A. A influência do UNICEF e da UNESCO na Educação Infantil contemporânea brasileira. Revista HISTEDBR On-line, Campinas, n 35, v. 9, p. 126-140, set. 2009. Disponível em: https://periodicos.sbu.unicamp.br/ojs/index.php/histedbr/article/vie w/8639618. Acesso em: 28 ago. 2018.

MATARAZZO, D. C. Análise Financeira de Balanços. 7. ed. São Paulo: Atlas, 2010.

MINAS GERAIS. Tribunal de Contas do Estado. Fiscalizando com o TCE: Minas Transparente. Disponível em:

https://fiscalizandocomtce.tce.mg.gov.br/\#/public/balanco. Acesso em: 14 ago. 2018.

SANTOS, J. B; SOUSA JUNIOR, L. Educação Infantil: 20 anos da primeira etapa da educação básica e os desafios do financiamento. Revista Contemporânea de Educação, Rio de Janeiro, v.12, p. 261284, maio/ago.2017. Disponível em: https://revistas.ufr.br/index.php/rce/article/view/3685. Acesso em: 19 ago. 2018. 
SILVA JUNIOR, S. D.; COSTA, F. J. Mensuração e Escalas de Verificação: uma Análise Comparativa das Escalas de Likert e Phrase Completion. Revista Brasileira de Pesquisa de Opinião,

Marketing e Mídia. São Paulo, Brasil, v. 15, p. 1-16, outubro, 2014. Disponível em:

http://www.revistapmkt.com.br/Portals/9/Volumes/15/1_Mensura\% C3\%A7\%C3\%A3o\%20e\%20Escalas\%20de\%20Verifica\%C3\%A7\%C3\% A30\%20uma\%20An\%C3\%A1 lise\%20Comparativa\%20das\%20Escalas \%20de\%20Likert\%20e\%20Phrase\%20Completion.pdf. Acesso em 17 jul. 2018

\section{SECRETARIA DO TESOURO NACIONAL. Sistema de Informações} Contábeis e Fiscais do Setor Público Brasileiro. Disponível em: https://siconfi.tesouro.gov.br/siconfi/pages/public/declaracao/declar acao_list.jsf. Acesso em: 27 jun 2018.

CÂMARA MUNICIPAL DE TEÓFILO OTONI-MG. Lei 6.658 de 11 de novembro de 2013 que DISPÕE SOBRE O PLANO PLURIANUAL DE GOVERNO DO MUNICÍPIO DE TEÓFILO OTONI PARA O PERÍODO 2014/2017. Teófilo Otoni-MG, 2013. Disponível em: https://fiscalizandocomtce.tce.mg.gov.br/\#/public/orcamento. Acesso em: 10 mar 2018 PREFEITURA MUNICIPAL DE TEÓFILO OTONI. Plano Municipal de Educação 2015/2024. No prelo 2015.

VERGARA, S. C. Projetos e Relatórios de Pesquisa em Administração. 14. ed. São Paulo: Atlas, 2013.

Submetido em: Junho/ 2020.

Aceito em: Fevereiro/ 2021. 